\title{
A question of honor(aria)
}

Honorarium: fee, especially for professional services normally rendered without payment (Oxford English Dictionary)

$\mathrm{O}$ ne of the main activities of the Canadian Association of Gastroenterology (CAG) is the organizing of professional education events, and the largest of these events is Canadian Digestive Diseases Week (CDDW). The CDDW is organized by members of the CAG for members of the CAG. The funds needed to run this meeting are generated from a number of sources - membership dues, sponsorship from pharmaceutical companies, sale of exhibit space, etc. These funds are used to pay for the convention facilities, for the audiovisual services, for the coffee breaks and lunches, and for the cost of bringing to our meetings the many experts who are on the program.

In the eight years that I have served on the Governing Board of the CAG, I do not recall any issue being discussed more frequently than the policy on reimbursement of speak- ers' expenses and the provision of honoraria. While there is general agreement that our current policy is comparable with that of other societies of gastroenterology, the issue that continues to be debated centres on the provision of honoraria and/or reimbursement of travel expenses to members of our own association who are asked to speak at the CDDW or to chair sessions at the CDDW. As shown in Table 1, the current CAG policy is to provide members of the CAG who are invited to speak at the CDDW with a flat-rate allowance of $\$ 250$ for each day of the meeting on which they make a presentation. Individuals who act as a chair of a session do not receive any honorarium. The rationale behind this policy, and one with which I personally agree, is that members of our association should be willing to perform services, such as chairing a session, for the good of the association. Members of the CAG Governing Board and members of the various CAG committees do not receive honoraria for the many hours that they provide to the CAG throughout the year. In my view, chairing a ses-

TABLE 1

Reimbursement policies for speakers at the annual meetings of various associations of gastroenterology

Members of the association

Non-members of the association

\begin{tabular}{lcccccc} 
Association & Honorarium & Airfare & Hotel & Honorarium & Airfare & Hotel \\
\hline American & US $\$ 500$ & No & No & US $\$ 500$ & Economy class \\
Australian & No & No & No & AUST $\$ 100$ per diem & Business class & For duration of meeting \\
Italian & No & No & No & No & Economy class & For duration of meeting \\
United European & Not applicable & Not applicable & Not applicable & No & Economy class & For duration of meeting \\
Canadian & CDN\$250 & No & No & US $\$ 500$ & Business class if flight & longer than 3 h; economy \\
& & & & & class otherwise
\end{tabular}


sion at the CDDW should be viewed as an honour. Many of our colleagues annually accept invitations to chair sessions at the American Gastroenterology Association meeting without receiving any honorarium or travel expenses (Table 1). Is it not reasonable to expect the same dedication to our own national association?

At this year's CDDW, there will not be any 'satellite symposia' sponsored by pharmaceutical companies. In the past, the pharmaceutical companies have looked after all of the financial aspects of these symposia, including the reimbursement of speakers and chairs. Different companies reimbursed speakers and chairs to different extents, and they were under no obligation to follow the CAG guidelines on reimbursement. Thus, a speaker at an industrysponsored symposium could have received much greater remuneration than a speaker on the nonsponsored portion of the CDDW program. This year, we will be introducing 'sponsored symposia' in place of the satellite symposia. Symposia topics were selected by our members, from the needs analysis performed at CDDW 2000. Companies interested in sponsoring a symposium were then 'matched' to topics close to the therapeutic areas served by their products. All financial aspects of the sponsored symposia will now be administered by the CAG, so the CAG reimbursement policy will be followed for all components of the CDDW.

I am writing this article to bring this contentious issue to the attention of the CAG membership at large. This is an issue that needs to be discussed openly. I encourage any of you who have an opinion on this topic to forward it to our executive director, Paul Sinclair, who will assimilate all of the responses (e-mail cagoffice@cag-acg.org or fax 905-829. 0242). I will also place this issue on the agenda of the Annual General Meeting, which will be held at 12:00 on Tuesday, February 27 at the Banff Springs Hotel. This article is clearly biased by my own opinion on this subject. I encourage those of you with dissenting views to make them known so that we can have a full and open discussion (and hopefully a resolution) of this issue.

John L Wallace PhD

President, The Canadian Association of Gastroenterology 


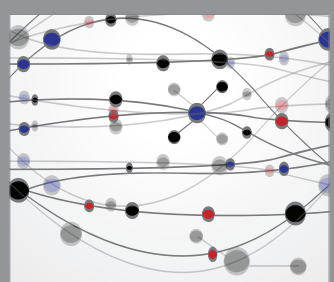

The Scientific World Journal
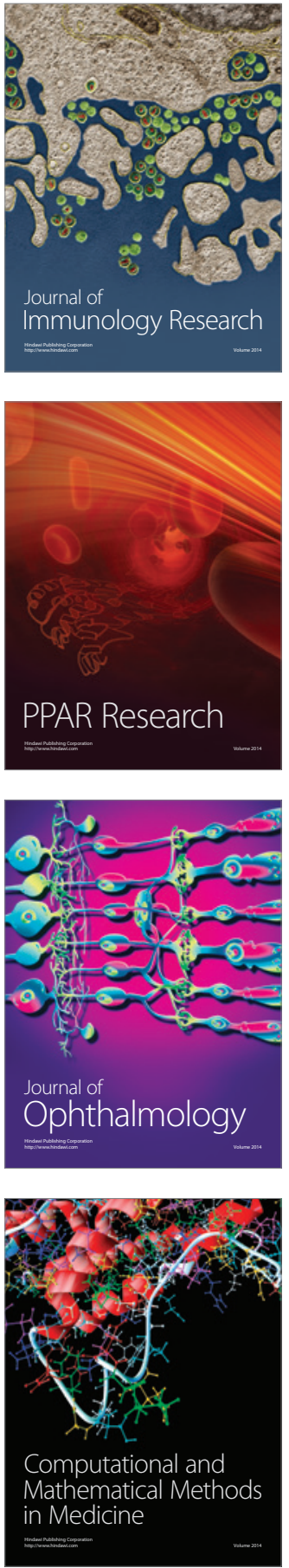

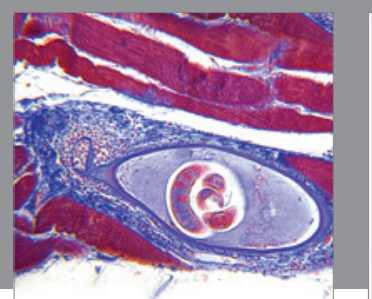

Gastroenterology Research and Practice

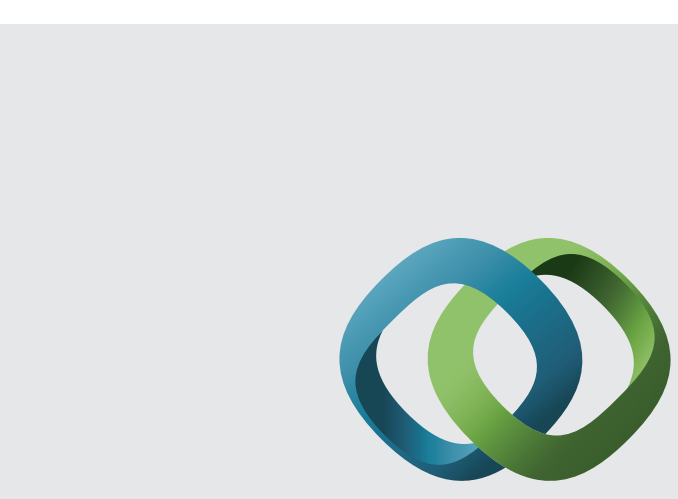

\section{Hindawi}

Submit your manuscripts at

http://www.hindawi.com
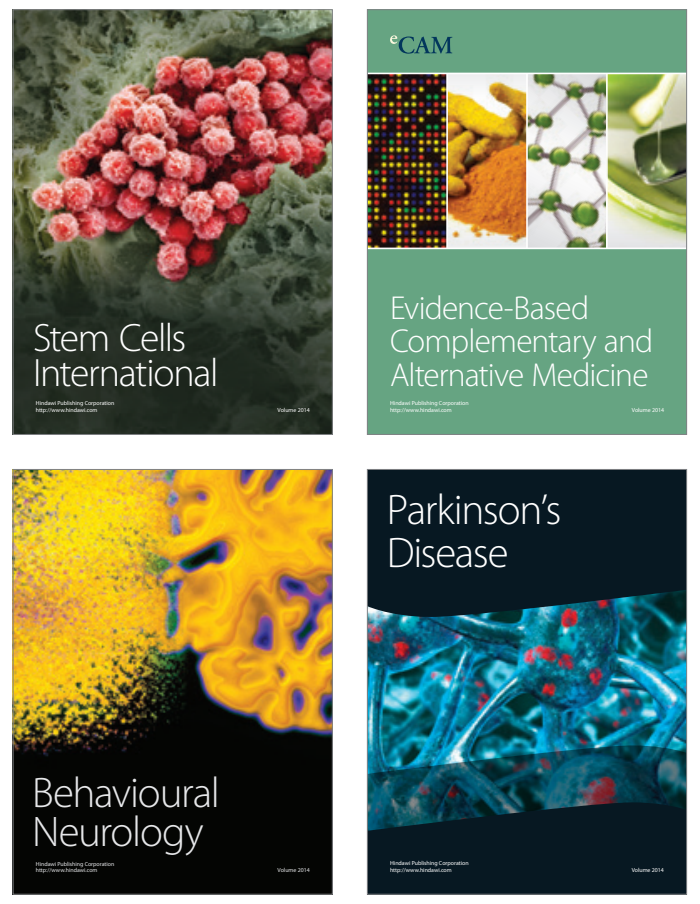
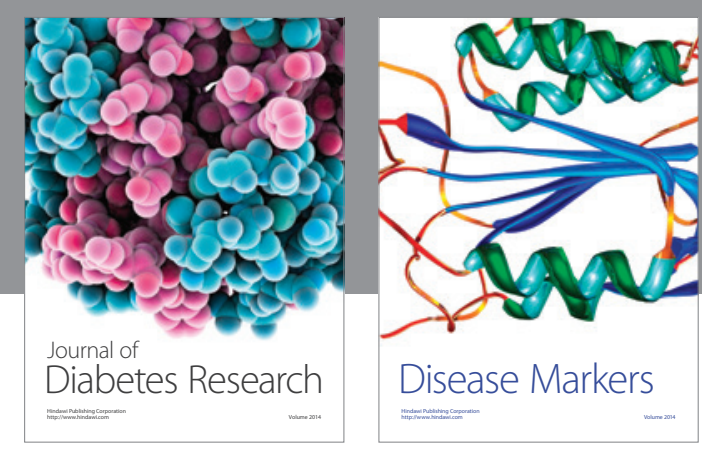

Disease Markers
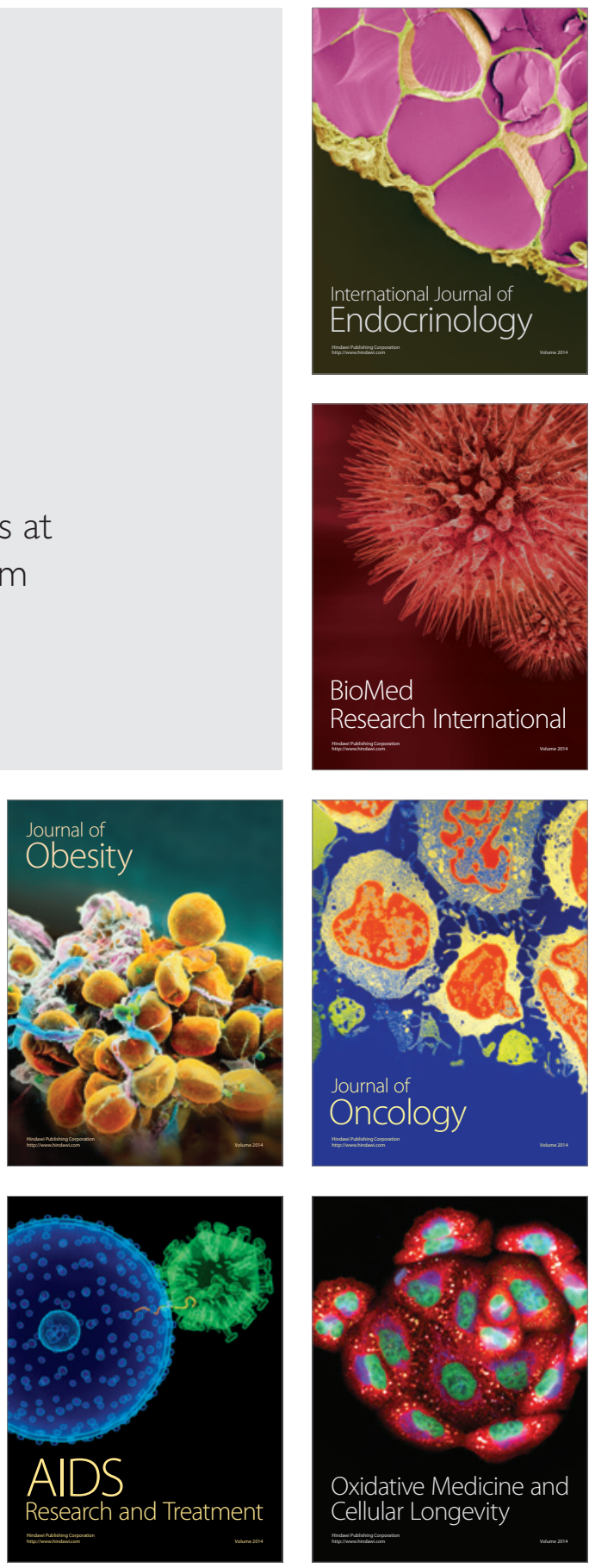